\title{
MONITORING LANDSCAPE CHANGES IN JAPAN USING CLASSIFICATION OF MODIS DATA COMBINED WITH A LANDSCAPE TRANSFORMATION SERE (LTS) MODEL
}

\author{
IPPEI HARADA ${ }^{1 *}$, KEITAROU HARA ${ }^{1}$, MIZUKI TOMITA ${ }^{1}$, \\ KEVIN SHORT ${ }^{1}$, JONGGEOL PARK ${ }^{1}$ \\ ${ }^{1}$ Department of Informatics, Tokyo University of Information Sciences, 4-1 Onaridai \\ Wakaba-ku,Chiba, 265-8501 Japan; *email: iharada@rsch.tuis.ac.jp
}

Received: $7^{\text {th }}$ September 2009, Accepted: $30^{\text {th }}$ October 2014

\begin{abstract}
Japan, with over $75 \%$ forest cover, is one of the most heavily forested countries in the world. Various types of climax forest are distributed according to latitude and altitude. At the same time, human intervention in Japan has historically been intensive, and many forest habitats show the influence of various levels of disturbance. Furthermore, Japanese landscapes are changing rapidly, and a system of efficient monitoring is needed. The aim of this research was to identify major historical trends in Japanese landscape change and to develop a system for identifying and monitoring patterns of landscape change at the national level. To provide a base for comparison, Warmth Index (WI) climatic data was digitalized and utilized to map potential climax vegetation for all of Japan. Extant Land Use Information System (LUIS) data were then modified and digitalized to generate national level Land Use/Land Cover (LU/LC) distribution maps for 1900, 1950 and 1985. In addition, MODIS data for 2001 acquired by the Tokyo University of Information Sciences were utilized for remote LU/LC classification using an unsupervised method on multi-temporal composite data. Eight classification categories were established using the ISODATA (cluster analyses) method; alpine plant communities, evergreen coniferous forest, evergreen broad-leaved forest, deciduous broad-leaved forest, mixed forest, arable land (irrigated rice paddy, non-irrigated, grassland), urban area, river and marsh. The results of the LUIS analyses and MODIS classifications were interpreted in terms of a Landscape Transformation Sere model assuming that under increasing levels of human disturbance the landscape will change through a series of stages. The results showed that overall forest cover in Japan has actually increased over the century covered by the data; from $72.1 \%$ in 1900 to $76.9 \%$ in 2001 . Comparison of the actual vegetation and the potential vegetation as predicted by WI, however, indicated that in many areas the climax vegetation has been replaced by secondary forests such as conifer timber plantations. This trend was especially strong in the warm and mid temperate zones of western Japan. This research also demonstrated that classification of moderate resolution remote sensing data, interpreted within a LTS framework, can be an effective tool for efficient and repeat monitoring of landscape changes at the national level. In the future, the authors plan to continue utilizing this approach to track rapidly occurring changes in Japanese landscapes at the national level.
\end{abstract}

Key words: Landscape change, Landscape Transformation Sere, Monitoring, MODIS, Remote sensing 


\section{INTRODUCTION}

Japan, with more than $75 \%$ of the land forested, ranks third in the world in terms of forest cover, following only Finland and Sweden. Warm ocean currents flowing on both sides of the islands bring relatively mild climate and abundant precipitation throughout the year, creating ideal conditions for forest growth. The extent of forest cover can be clearly seen in Figure 1, which shows land cover distribution for 2001 based on classification of remote sensing data.

The Japanese islands stretch a long way in the north-south direction, and regional climate vary from warm-temperate in the south to sub-arctic in the far north. Japan is also a highly mountainous country, with substantial subalpine and alpine zones. Given these conditions, Japan is home to a great variety of forest types. The form of the naturally occurring old-growth forest is determined primarily by temperature related factors. Two-dimensional spatial analysis of Japanese vegetation distribution, utilizing latitude and altitude, were conducted by Ohsawa (1990, 1995). In addition, Kira (1976) mapped potential vegetation zones using the Warmth Index (WI).

Fig. 1: LU/LC map of Japan, based on classification of MODIS data, 2001

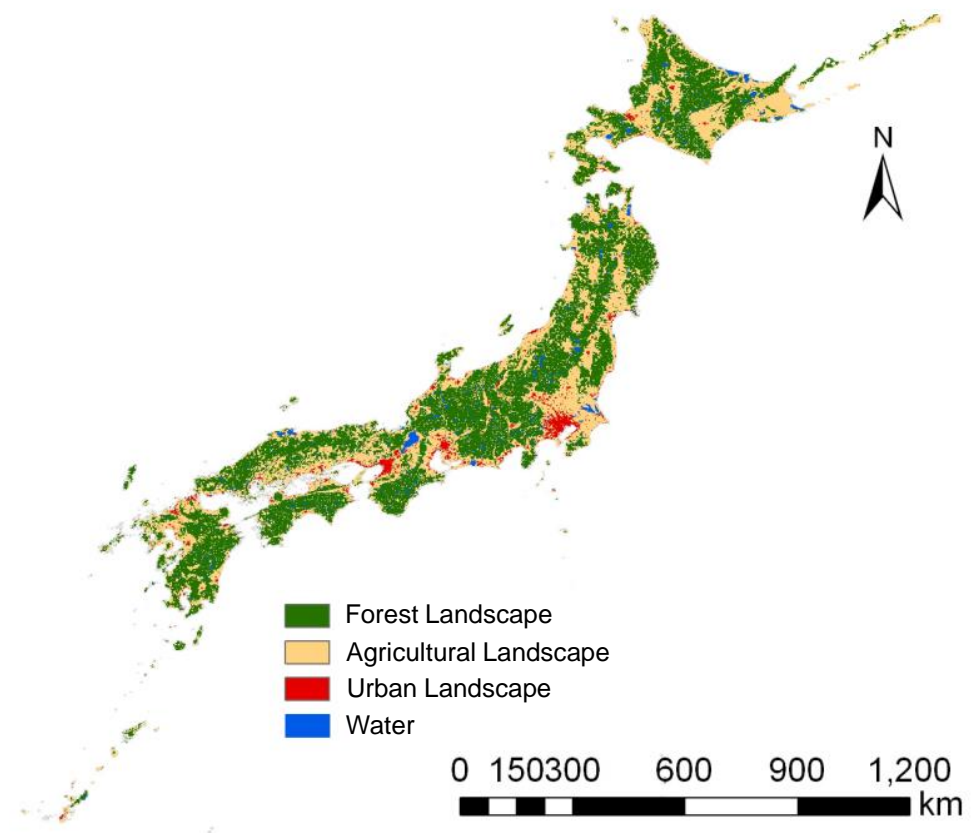

Japanese forests, however, have been subject to severe disturbance due to human activities. Irrigated rice agriculture began about 3000 years ago, and since then many old growth forests, especially in the warm-temperate and mid-temperate zones, have been converted to secondary woodlands and forestry plantations. Over the past century or so, urbanization and industrial development have also impacted natural forests (Westhoff, 1983; Haber, 1990; Goodie, 1993). In addition, current global-level climate change may also affect the distribution of forest types. Proper management of ecosystems and biodiversity thus requires not only clear understanding of historic patterns and current status of Japanese forests, but also an efficient system for monitoring rapid changes. 
The research is designed with this need in mind. To begin with, the potential vegetation for the entire country was mapped employing WI (Kira et al., 1976; Nogami, 1994). Next, extant LUIS land use/land cover (LU/LC) maps, available for 1900, 1950 and 1985, were digitalized and compared (Harada et al., 2010). Finally, wide-scale remote sensing data (MODIS) was utilized to map the current LU/LC for all of Japan. Based on these data, the research identified major trends in forest change over the past century, and evaluated MODIS as a tool for monitoring future changes.

\section{Potential Vegetation}

\section{Methods}

WI is defined as the annual sum of monthly mean temperature above 5 degrees Celsius excluding negative values. The WI value is a function of location (latitude and longitude, distance to coast, etc.), altitude and orientation. This concept was first applied in Japan by Kira et al (1976), and was later modified by Nogami (1994). This research employs Nogami's model utilising WI values to divide Japan into five climatic zones: warm-temperate, mid-temperate, cool temperate, subarctic (subalpine) and arctic (alpine). As a first step in this research, basic climate data were obtained from a $1 \mathrm{~km}$ grid map of monthly air temperature in 1987 prepared by the Japan Meteorological Agency. The data were digitalized and used to generate a climatic zone master map, shown in Figure 2.

\section{Fig. 2: Climatic zones defined by Warmth Index (WI) (after Harada et al., 2011)}

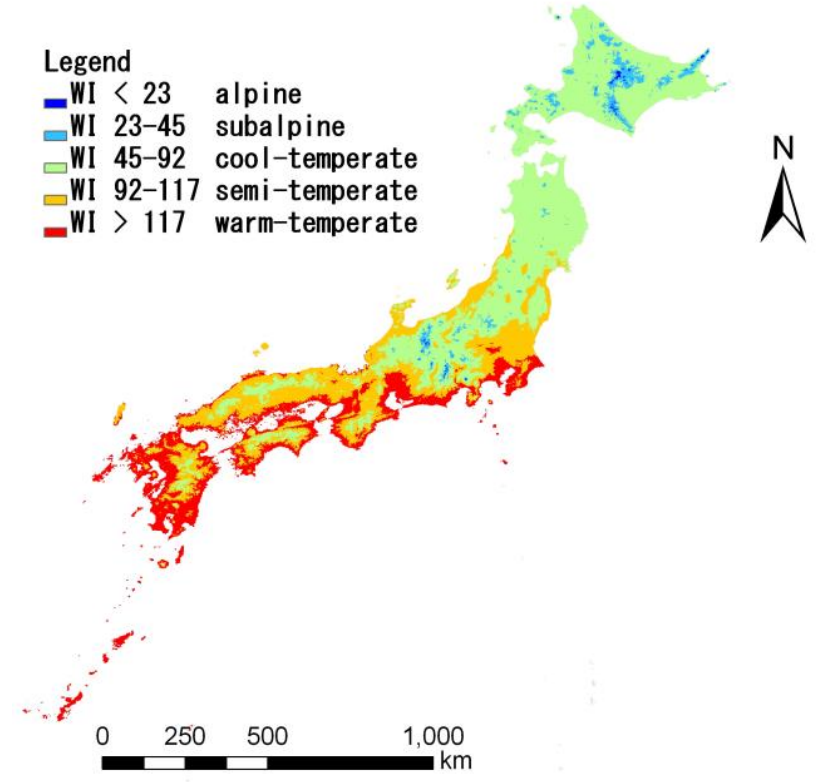

Next, potential vegetation forest types were assigned to each of the five climatic zones. These vegetation types were also based on Nogami, with some small modifications in English nomenclature. The five climatic zones and the corresponding potential vegetation are shown in Table 1. This data was then used to generate a map of potential vegetation for all of Japan. 
Harada I., Hara K., Tomita M., Short K., Park J.: Monitoring landscape changes in Japan using classification of MODIS data combined with a Landscape Transformation Sere (LTS) model

Tabale 1: Five potential forest vegetation zones in Japan based on climatic data (after Nogami, 1994)

\begin{tabular}{ccc}
\hline Forest vegetation zone & Climatic zone & Warmth Index (WI) \\
\hline Dwarf pine forest/grassland & alpine & $0-23$ \\
\hline Evergreen coniferous forest & subalpine & $23-45$ \\
\hline Deciduous broad-leaved forest & cool-temperate & $45-92$ \\
\hline Evergreen coniferous/deciduous broad-leaved forest & semi-temperate & $92-117$ \\
\hline Evergreen broad-leaved forest & warm-temperate & $117-238$ \\
\hline
\end{tabular}

\section{Results}

The results of potential vegetation for Japan as predicted by WI are shown in Figure 3. The evergreen broad-leaved forest, characteristic for the warm-temperate zone, represents the northern limit of the great Asian forest that stretches from the eastern coast of The Himalayas clear across to the Pacific shore. This warm temperate forest, dominated by chinquapin (Castanopsis), live oak (Quercus subgenus Cyclobalanopsis) and laurel (Machillus) spreadsextensively in Japan due to the ameliorating effects of the Kuroshio and Tsushima warm currents that flow along the Pacific Ocean and the Sea of Japan coasts of the archipelago.

Fig. 3: Potential vegetation of Japan as predicted by WI

Legend

Dwarf pine forest/grassland

Evergreen coniferous forest

Deciduous broad-leaved forest

Evergreen coniferous/deciduous broad-leaved forest

Evergreen broad-leaved forest

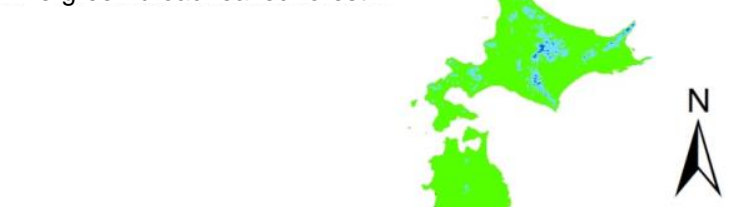

$0 \quad 250 \quad 500 \quad 1,000$
$\mathrm{~km}$ 
The deciduous broad-leaved forest, characteristic for the cool temperate zone and dominated by beech (Fagus) and deciduous oak (Quercus), is concentrated in southern Hokkaido and northern and central Honshu, but is also found on mountainsides further south and west. The mid-temperate forest, characterized by evergreen conifers such as Tsuga and Abies firma, can be considered to be a transitional zone. Please note that in some scientific work and vegetation maps much of the area of this forest is included in the evergreen broad-leaved zone. The alpine zone vegetation consists primarily of dwarf pine (Pinus pumila), mixed with grassland and low stands of alder, willow, rowan and deciduous oak; while the subalpine vegetation is dominated by evergreen conifers such as Abies mariessii and Picea.

\section{ChANGES IN LU/LC 1900 1985}

\section{Methods}

The major part of the Land Use Information System (LUIS) map analyses was reported in Japanese in the previous paper (Harada et al., 2011). The results are summarized here in English. The original LUIS maps were produced by Himiyama (Himiyama et al., 1995; Himiyama, 1998, 1999), from symbols and other LU/LC data on historic 1:50,000 scale topographic maps. Based on the map information, Himiyama assigned a dominant LU/LC category for each $2 \mathrm{~km}$ grid. The original research employed 24 different LU/LC categories (Table 2, left side).

Table 2: LU/LC categories for LUIS Land Use Information System analysis (after Harada et al., 2011)

\begin{tabular}{l|l}
\hline \multicolumn{1}{c|}{ original Himiyama } & Harada et al. 2011 \\
\hline $\begin{array}{l}\text { dry paddy field } \\
\text { paddy field } \\
\text { marshy rice field } \\
\text { dry field/grassland } \\
\text { mulberry field } \\
\text { tea plantation } \\
\text { orchard }\end{array}$ & \\
tree crops & arable land \\
\hline urban & \\
\hline broad-leaved forest & broad-leaved forest \\
\hline $\begin{array}{l}\text { coniferous forest } \\
\text { creeping pine }\end{array}$ & coniferous forest \\
\hline mixed forest & mixed forest \\
\hline $\begin{array}{l}\text { bamboo forest } \\
\text { mitsumata plant } \\
\text { palm tree }\end{array}$ & other forest \\
\hline $\begin{array}{l}\text { pasture land } \\
\text { rough land } \\
\text { gravely sand } \\
\text { marshy land } \\
\text { golf course }\end{array}$ & \\
\hline river & open area \\
lake & \\
saltpan & water \\
\hline
\end{tabular}


In this research, Himiyama's LU/LC maps were digitalized, and for research purposes the original 24 categories were consolidated to eight: agricultural land, urban area, broad-leaved forest, coniferous forest, mixed forest, other forest, open area and water (Table 2, right side). These categories correspond well with the abilities of remote sensing data analysis to distinguish LU/LC properties, and thus facilitate comparing the results with continuing remote sensing research.

Based on the digitalized LUIS data, National level LU/LC distribution maps were generated for 1900, 1950 and 1985, shown respectively in Figures 4-a, 4-b, and 4-c. The results from these three maps were then compared to identify major patterns of forest change over the 85 year period from 1900 to 1985 .

Fig. 4-a: LU/LC for 1900 based on LUIS data

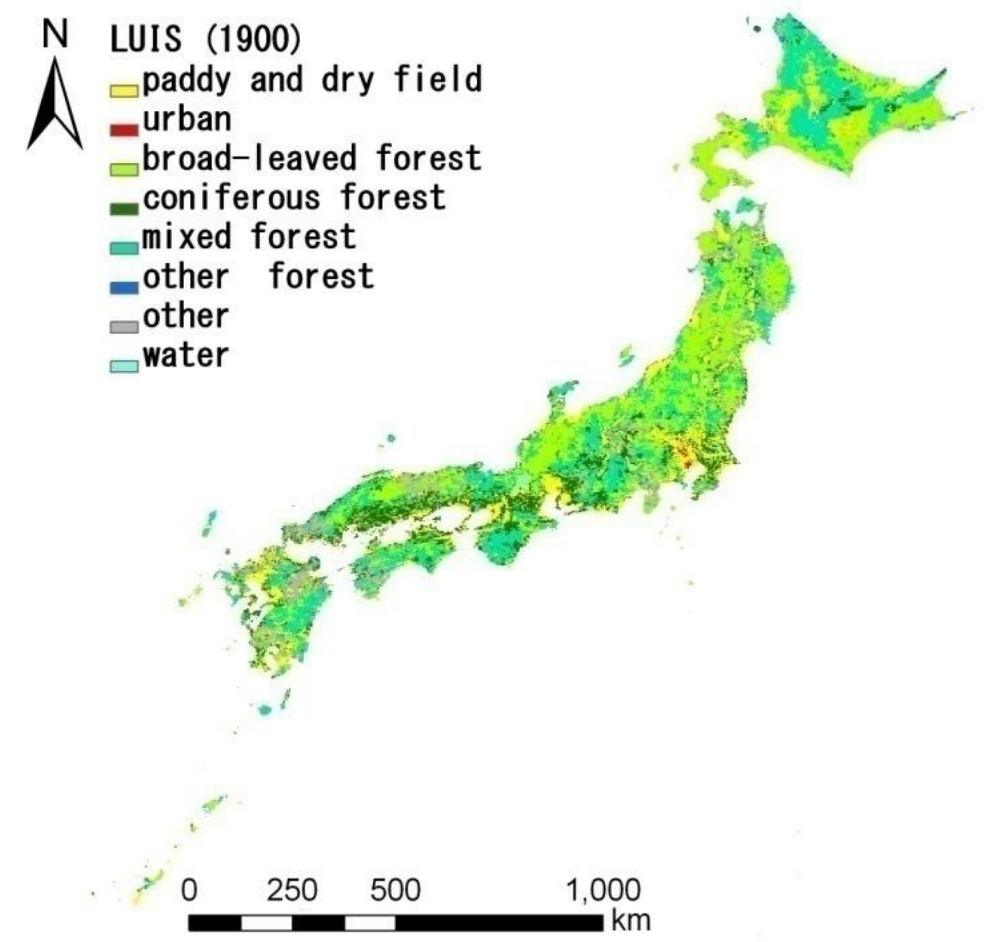


Fig. 4-b: LU/LC for 1950 based on LUIS data

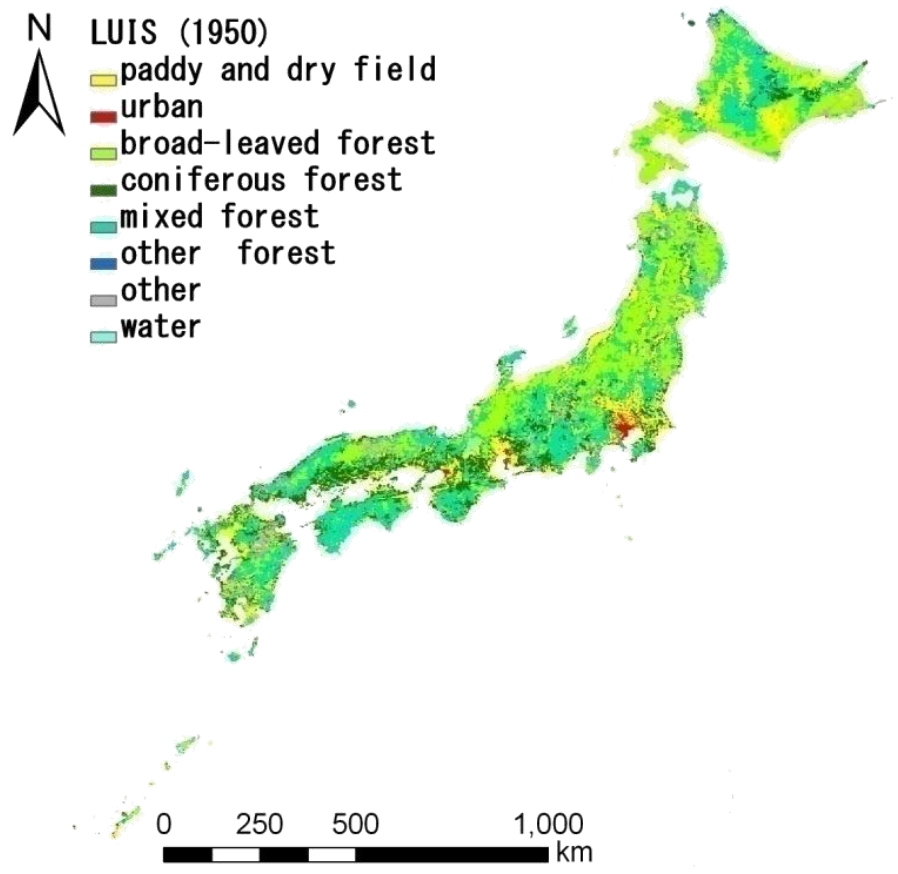

Fig.4-c: LU/LC for 1985 based on LUIS data

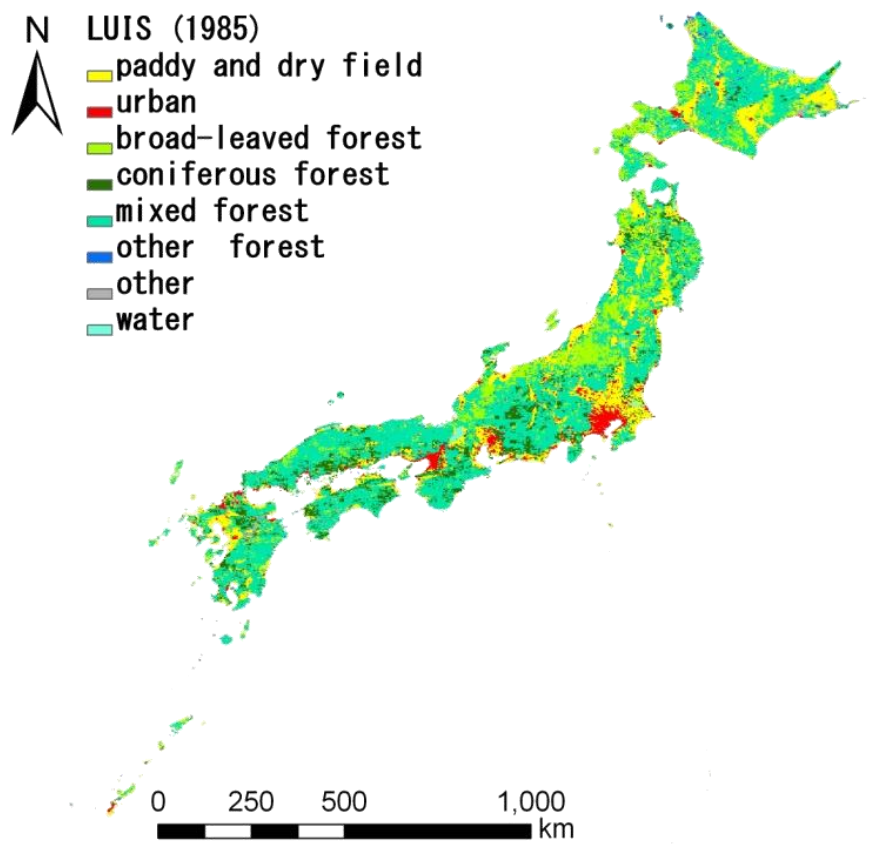




\section{Results}

As can be seen in the LUIS maps, the percentage of urban area increased from $0.4 \%$ in 1900 to $1.3 \%$ in 1950 and $4.0 \%$ in 1985 . The total area occupied by the four forest categories, however, increased as well; from $72.1 \%$ in 1900 to $74.3 \%$ in 1950 and $75.3 \%$ in 1985 . Over the 85 year period, broad-leaved forest decreased by $15.1 \%$, from $158,472 \mathrm{~km}^{2}$ to 77,248 $\mathrm{km}^{2}$; and coniferous forest by $3.1 \%$, from $68,536 \mathrm{~km}^{2}$ to $51,896 \mathrm{~km}^{2}$. Mixed forest, on the other hand, increased by $21.2 \%$, from $159,028 \mathrm{~km}^{2}$ to $273,888 \mathrm{~km}^{2}$. This increase is most likely due to an aggressive national forestry policy implemented after 1950, under which broad-leaved forests were cut down and replaced by timber plantations of Cryptomeria and Chaemocyparis (Miyawaki, 1977). Although these commercial timber species are conifers, when viewed on a $2 \mathrm{~km}$ grid they are often mixed with remnant patches of broad-leaved trees, and the land use is thus classified as mixed forest.

Changes within the three forest categories are shown in Figure 5. As can be seen, only $8,388 \mathrm{~km}^{2}(1.6 \%)$ of the 1900 broad-leaved forest area changed to coniferous forest by 1985 ; but $84,240 \mathrm{~km}^{2}(15.6 \%)$ changed to mixed forest. Of the 1900 coniferous forest area, 2,172 $\mathrm{km}^{2}(0.4 \%)$ changed to deciduous forest, and $34,164 \mathrm{~km}^{2}(6.3 \%)$ to mixed forest. Of the 1900 mixed forest area, $20,688 \mathrm{~km}^{2}(3.8 \%)$ changed to broad-leaved forest, and $13,296 \mathrm{~km}^{2}(2.5 \%)$ to coniferous forest. In total areas that remained forested but changed forest category accounted for $30.2 \%$ of the total national forest area.

Fig. 5: Changes within the three forest categories, 1900 and 1985, based on LUIS data (after Harada et al., 2011)

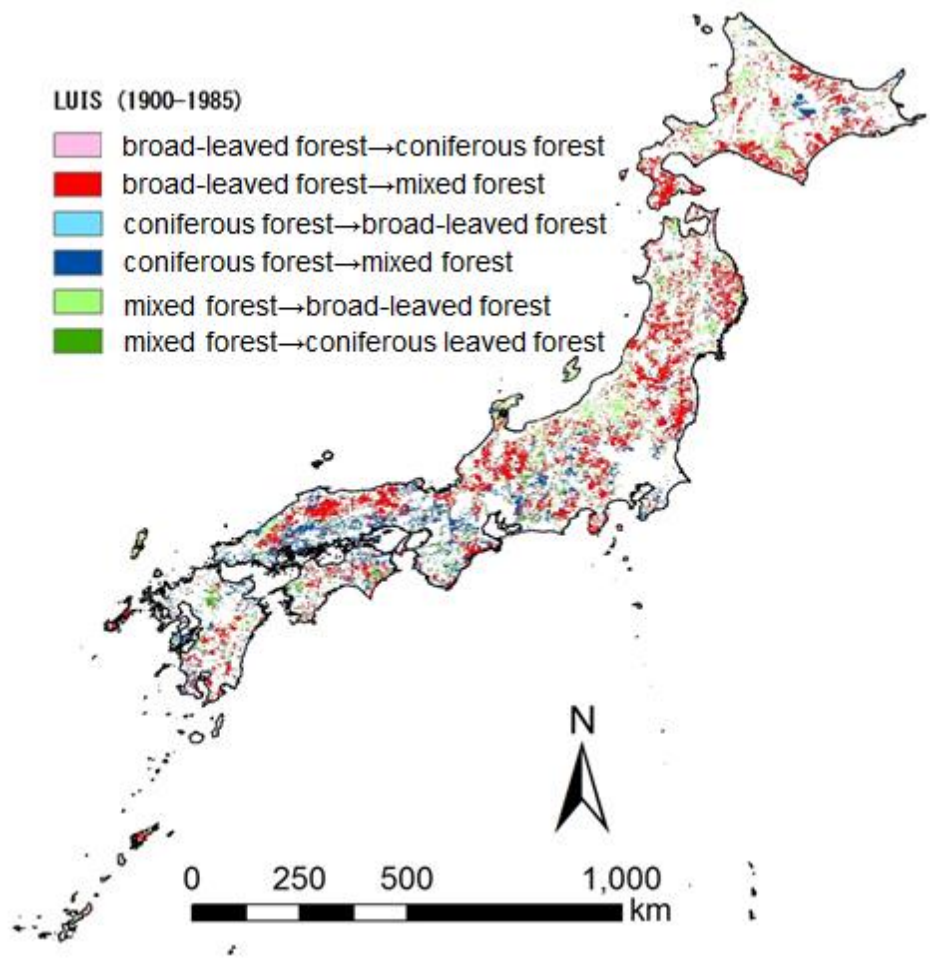




\section{NATIONAL LEVEL MODIS LU/LC ClassifiCATION}

\section{Background}

Japan's forest cover and land use patterns are currently in a period of rapid change. Areas on the outskirts of large cities are frequently swallowed up by suburban development. In contrast, some rural areas have become depopulated, leading to abandonment of historic land use and forest management practices. In addition, vegetation can change dramatically due to large-scale natural disasters such as earthquakes, tsunami, floods, landslides and volcanic eruption. In the future, climate change can also be expected to cause shifts in the distribution of forest types. In this period of rapid change, wise management of resources and conservation of biodiversity requires an efficient system for timely tracking of changes in land use and forest cover at the national level. Moderate resolution remote sensing satellite data, such as MODIS (Moderate Resolution Imaging Spectroradiometer), shows great promise as a tool for this purpose.

MODIS is a key instrument aboard the Terra (EOS AM1) and Aqua (EOS PM1) satellites launched by NASA. Terra's orbit around the Earth is timed so that it passes from north to south across the equator in the morning, while Aqua passes south to north over the equator in the afternoon. Terra/MODIS and Aqua/MODIS thus view the entire Earth's surface every 1 to 2 days, acquiring data in 36 spectral bands, or groups of wavelengths.

MODIS data (MOD09), although available only in relatively low spatial resolutions of 250 $\mathrm{m}$ and $500 \mathrm{~m}$, can be acquired every day, and is thus suitable for understanding both seasonal variations and short-term patterns of change. In addition, the data is available over a wide area, and can thus be used to identify and monitor general landscape patterns and changes at the level of the whole Japan. At Tokyo University of Information Sciences, Terra MODIS data has been periodically acquired and archived since 2000. Since 2002, data from the Aqua satellite has been added, allowing acquisition several times daily.

\section{Data}

This research employed MODIS data covering the entire Japanese archipelago, acquired by Tokyo University of Information Sciences. A total of 223 Terra/MODIS images from the year 2001 (34 in July, 41 in August, 51 in September, 52 in October and 45 in November) were utilised to classify LU/LC for all of Japan.

The datasets employed in this research were MOD09 Surface Reflectance Bands1-7, and MOD03. Map projection was accomplished by using MOD03 positioning data and MOD09

(Level2) reflectance rate data with atmospheric corrections. Composite monthly data (July to November) were derived from the MOD09 (500 m resolution) data base. Maximum Value Composite (MVC) utilizing Normalized Difference Vegetation Index (NDVI) images were used to produce monthly mosaic images, and the effects of cloud cover were removed to make the monthly composite images. This MVC method derives the maximum NDVI value based on the assumption that the NDVI of clouds will be minimal (Holben, 1986). The observed maximum NDVI value, however, usually includes data obtained when the satellite is at a high sensor zenith angle (Roujean et al., 1992; Cihlar and Huang, 1994), so that only data acquired at an angle of less than 40 degrees are utilised.

\section{Classification}

The target region was divided into two parts; eastern Japan, from the Nagoya area north through the island of Hokkaido; and western Japan, from the Nagoya area south and west through the Ryukyu Islands. Land cover classification was implemented using an unsupervised classification method on multi-temporal (July through November) composite 
(total 40 channels) data. Eight classification categories were established using the ISODATA (cluster analysis) method. These were: alpine plant communities, evergreen coniferous forest, evergreen broad-leaved forest, deciduous broad-leaved forest, mixed forest, arable land (irrigated rice paddy, non-irrigated, grassland), urban area, and river and marsh. Separate scale LU/LC maps were generated for the northeast and southwest, and were checked for accuracy using extant vegetation maps, including the LUIS (1985) maps, greenery maps (Miyawaki, 1977) and Google maps.

National level LU/LC maps for Japan include the previously-discussed LUIS maps by Himiyama (1995) and Himiyama et al. (1998, 1999); as well as the 1:50,000 scale Actual Vegetation Maps produced by the Ministry of Environment (MOE) between 1979 and 1986. The latest date for Actual Vegetation Maps covering all of Japan, however, is 1999. In 1999 MOE started the $6^{\text {th }}$ and $7^{\text {th }}$ Mapping Programs, using 1:25,000 scale maps. As of March 2013; however, only $68 \%$ of the national land area had been surveyed, with the time required for full completion of a national level map estimated to be more than 20 years. Under these conditions, supervised classification would be difficult and that is why the unsupervised ISODATA method was adopted.

\section{Results}

Classification Results

The results for LU/LC classification of the 2001 MODIS data are shown for eastern Japan and western Japan respectively in Figures 6-a) and 6-b). As can be seen, extensive arable land is found only along the lower reaches of the major river systems, and urban areas are concentrated at river mouths and along the coast, especially in the southwest.

Fig. 6-a: Land use/cover (LU/LC) in eastern Japan based on Terra/MODIS data (2001)

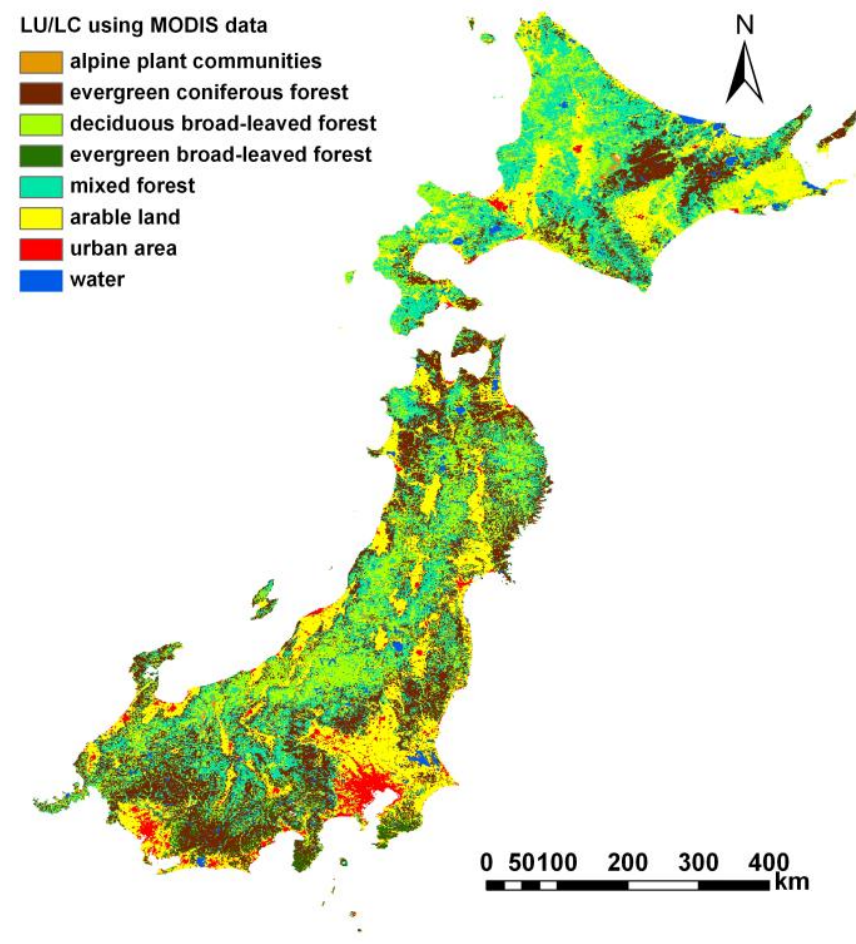


Deciduous broad-leaved forest is distributed in wide swaths in eastern Hokkaido, central and northern Honshu, and the northern part of western Honshu. The dark crimson evergreen coniferous forest can be seen to dominate large areas of Kyushu, Shikoku and south-central Honshu. Most of this forest type is contained in commercial timber plantations of Cryptomeria and Chaemocyparis (Hayashi, 1990; Fukushima and Iwase, 2005). Evergreen broad-leaved forest, the potential climax vegetation for much of the warm-temperate zone, can be seen to be rare and highly fragmented.

Fig. 6-b: Land use/cover (LU/LC) in western Japan based on Terra/MODIS data (2001)

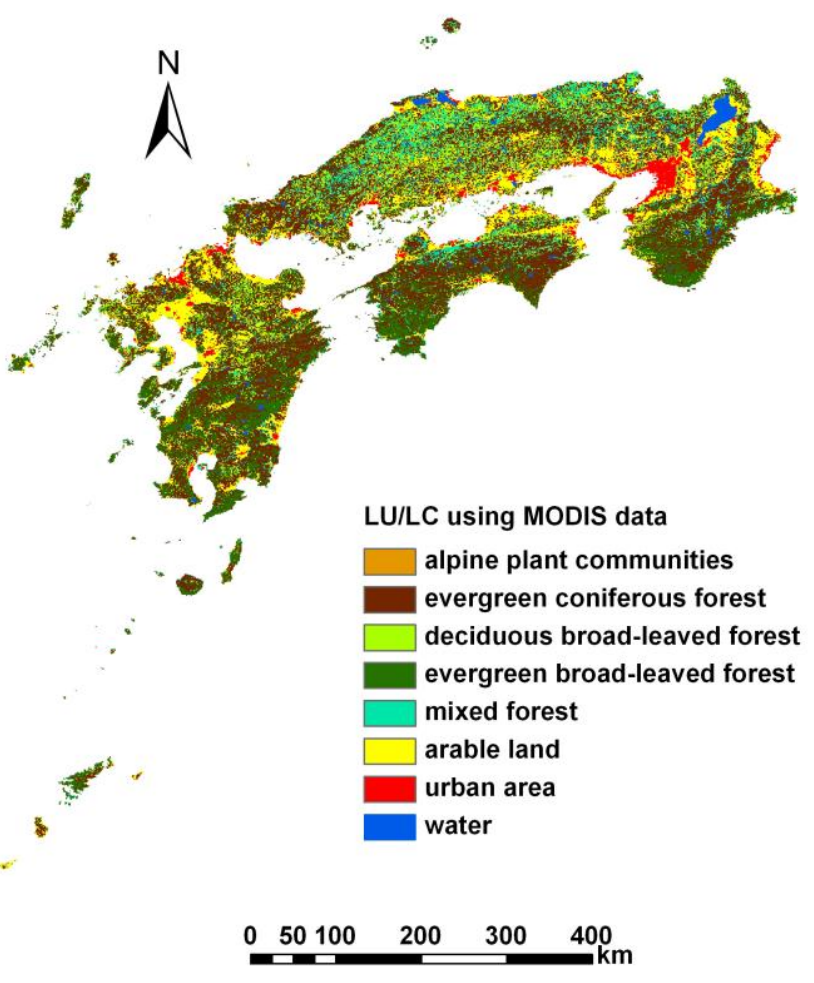

\section{COMPARISON OF MODIS ClASSIFICATION RESULTS AND POTENTIAL VEGETATION PREDICTED BY WI}

The results of the MODIS classifications were collated with the map of potential vegetation as predicted by Warmth Index. The results are shown respectively for the eastern and western regions in Figures 7-a) and 7-b). As can be seen, in the eastern region deciduous broad-leaved forest, evergreen coniferous forest and mixed forest are concentrated in the cool-temperate zone. In the western region the evergreen broad-leaved forests are found mostly in the semi-temperate and warm-temperate zones. Evergreen broad-leaved forests are considered to be the typical old-growth forest of these areas, but as can be seen, have been severely reduced in area. The largest forest cover in the southwestern region is the evergreen coniferous forest, reflecting an extensive program for developing commercial timber 
Harada I., Hara K., Tomita M., Short K., Park J.: Monitoring landscape changes in Japan using classification of MODIS data combined with a Landscape Transformation Sere (LTS) model

plantations implemented in the post-war years. The results seen here indicate that not only do eastern and western Japan differ in climate and potential vegetation, but that forests in these two regions have experienced different levels of human intervention throughout Japanese history.

Fig. 7-a: LU/LC in eastern Japan according to climatic zone

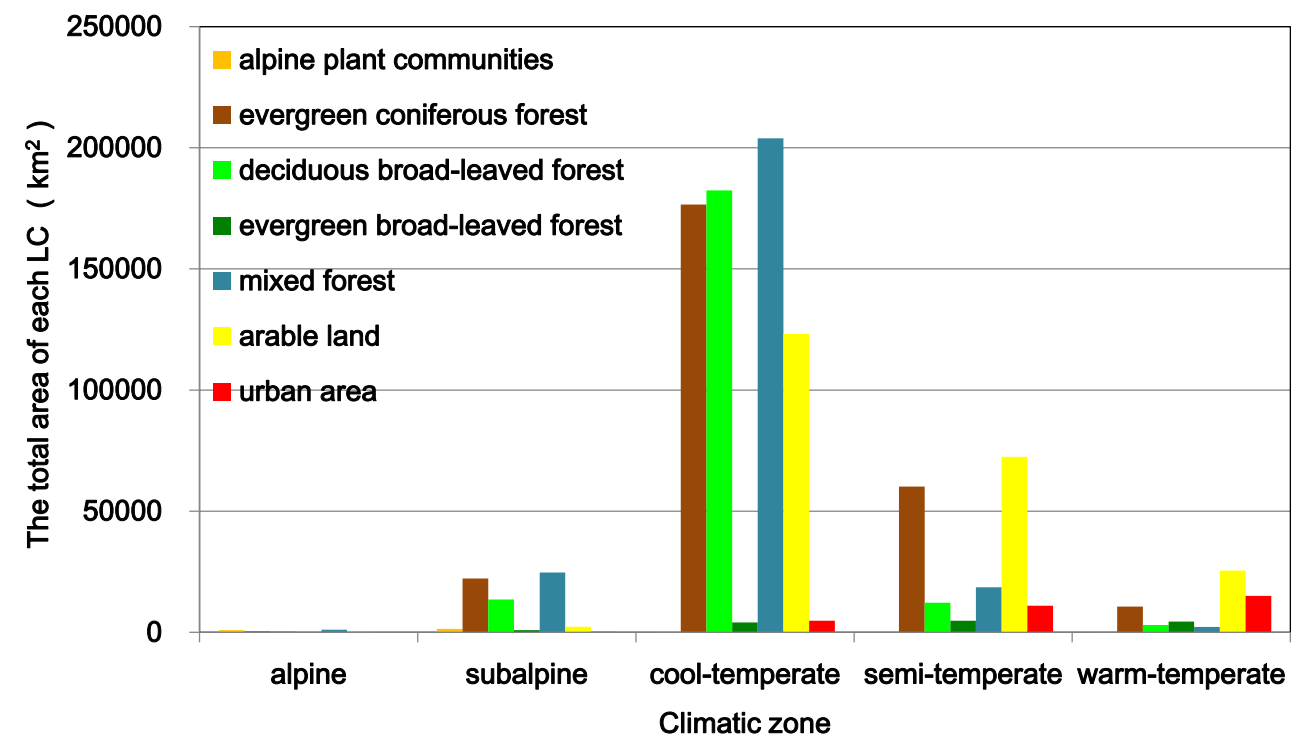

Fig. 7-b: LU/LC in western Japan according to climatic zone

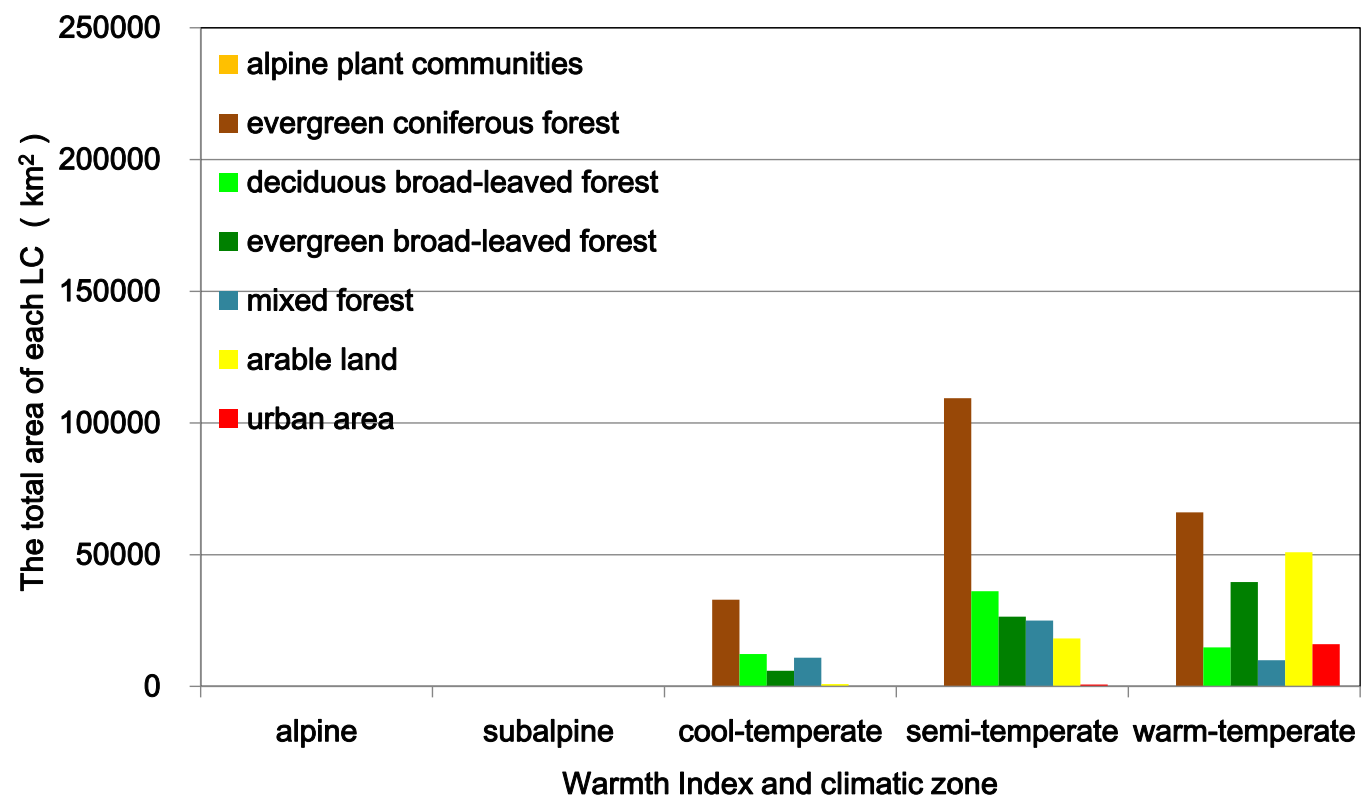




\section{INTERPRETATION OF RESULTS USING LANDSCAPE TRANSFORMATION SERE (LTS) MODEL}

The authors (Hara et al., 2010) have developed a model, called the Landscape Transformation Sere (LTS), for interpreting changes in land cover and land use patterns and vegetation as caused by increasing levels of human activities. In this model, which was developed primarily for use in areas of East Asia where the potential vegetation is some type of forest, it is assumed that under increasing levels of human disturbance the landscape will change through a series of stages. The model is shown in Figure 8. On the left are the various climax forests $(\mathrm{CF})$, which under the influence of human activities change into secondary forests (SF). These in turn change into grasslands (GL), arable land and finally villages and urban areas. In Japan, for example, a typical LTS series would start with evergreen broad-leaved or deciduous broad-leaved primary forests. Under the influence of human intervention these forests change into secondary forest landscapes such as oak coppices, conifer timber plantations, bamboo groves or fruit and nut orchards. Further intervention causes the landscape to move into a grassland stage, specified by livestock pastures or 'kaya-ba' thatch fields (managed fields of Miscanthus silver grass used as roof thatch). Still further, the land is converted to hatake (non-irrigated arable upland fields used primarily to grow vegetables) or irrigated rice paddies; and finally to rural, suburban or urban residential, commercial or industrial areas. It should be noted; however, that this LTS represents a general trend. In some cases the landscape can jump over stages; and can also move in the opposite direction in cases where the human intervention is removed. Abandoned dry fields, for example, soon revert to grasslands and then to secondary woodlands. Given sufficient time, the landscape will then eventually return to the original $\mathrm{CF}$ vegetation.

Fig. 8: Typical Landscape Transformation Sere (LTS) model (after Hara et al., 2009)

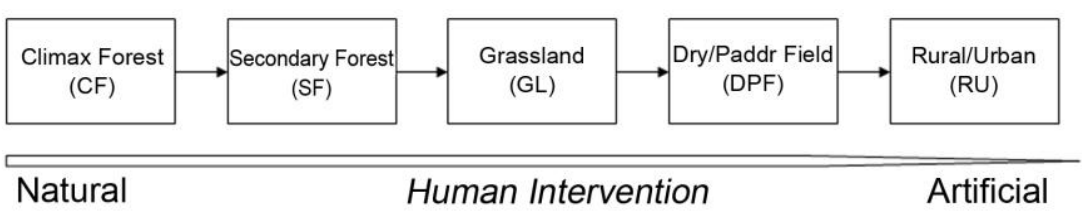

The LUIS section of this research, for example, was able to identify areas where the type of landscape changed between 1900 and 1985. As can be seen in Figure 9, some areas changed from forest to agricultural or urban and others from agricultural to urban. These changes represent the LTS moving to the right, in the direction of increasing human intervention. On the other hand, there were areas that changed from open area to forest, moving in the opposite direction, towards a lower level of human intervention. In some areas, by the end of the $19^{\text {th }}$ century the vegetation was disturbed to the point where it turned into bare slopes (Toyohara, 1984). Many of these bare areas were then reforested during the $20^{\text {th }}$ century. 
Harada I., Hara K., Tomita M., Short K., Park J.: Monitoring landscape changes in Japan using classification of MODIS data combined with a Landscape Transformation Sere (LTS) model

Fig. 9: Areas of Japan that changed LU/LC from 1900-1985 based on LUIS data

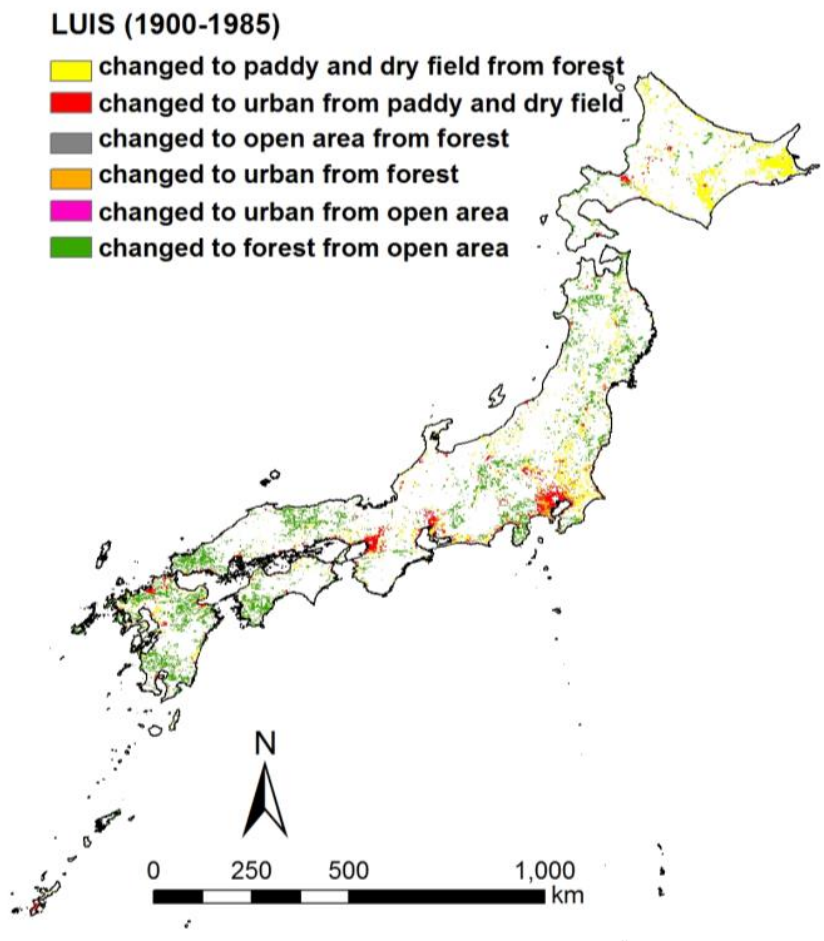

\section{CONCLUSIONS AND DISCUSSIONS}

This research identified the major landscape changes in Japan during the course of the $20^{\text {th }}$ century. Surprisingly, overall forest cover actually increased during this period, from $72.1 \%$ in 1900 to $74.3 \%$ in $1950,75.3$ in 1985 and $76.9 \%$ in 2001. The type of forest landscape; however, changed significantly. A noticeable decrease in broad-leaved forests, which are representative of the climax vegetation in many areas, was accompanied by an increase in commercial timber plantations (Miyawaki, 1977). As can be seen in Figure 7-b), the actual extent of climax forest in western Japan is especially low when compared to the distribution as predicted by WI predictions, is especially low.

This research also demonstrated that classification of middle resolution remote sensing data such as MODIS, combined with a LTS framework, can be an effective tool for efficient and timely monitoring of landscape changes at the national level. In the future, the authors plan to continue utilising this approach to track rapidly occurring changes in Japanese landscapes, both at the national level and concentrating in areas that are impacted by national disasters such as earthquakes, tsunami, floods, volcanic eruptions and landslides.

\section{ACKNOWLEDGEMENTS}

This research was supported in part by the MEXT Strategic Research Infrastructure Formation Project "Research project for sustainable development of economic and social 
structure dependent on the environment of the eastern coast of Asia (TUIS)"; by the Environment Research and Technology Development Fund (1-1405) of Ministry of Environment, Japan; and by a MEXT Japan grant-in-aid for scientific research (No. 26350403).

\section{REFERENCES}

Chihlar, J., Huang, F., (1994). Effect of atmospheric correction and viewing angle restriction on AVHRR data composites. Canadian Journal of Remote Sensing, 20(2), 132-137.

Fukushima, T., Iwase, T. (eds.) (2005). Vegetation of Japan. Asakura, Tokyo, 153 pp. (in Japanese)

Goudie, A., (1993). The Human Impact of the Natural Environment. $4^{\text {th }}$ ed. Blackwell Publishers, Oxford, 454 pp.

Haber, W., (1990). Using landscape ecology in planning and management. In Zooneveld, I.S. \& Forman, R.T.T. (eds.), Changing Landscapes: An Ecological Perspective (p. 217-232). Springer-Verlag, New York.

Hara K., Harada I., Tomita M., Short K., Park J., Simojima H., Fujihara M., Hirabuki Y., Hara M., Kondoh A., (2010). Landscape transformation sere: in which directions will our landscape move and how can we monitor these changes. Institute of Landscape Ecology, Slovak Academy of Sciences, Bratislava, Slovak Republic, 165-172.

Harada, I., Matsumura T., Hara, K., Kondoh, A., (2011). Spatial analysis of changes in Japanese forests during the process of modernization, Landscape Ecology and Management, 16(1), 17-32. (in Japanese with English abstract)

Hayashi, I., (1990). Vegetation Geography. Daimeido, Tokyo, 269 pp. (in Japanese)

Himiyama, Y., Arai, T., Kubo, S., Murayama, Y., Nogami, M., Ota, I. (eds), (1995). Atlas-Environmental change in Modern Japan. Asakura, Tokyo, 187 pp. (in Japanese with English abstract)

Himiyama, Y., (1998). Land use/cover changes in Japan: from the past to the future. Hydrological processes, 12, 1995-2001.

Himiyama, Y., (1999). Historical information bases for land use planning in Japan. Land use policy, 16, 145-151.

Holben, B.N., (1986). Characteristics of maximum-value composite images from temporal AVHRR data. International Journal of Remote Sensing, 7(11), 1417-1434.

Kira, T., (1976). Terrestrial Ecosystems. Kyoritsu, Tokyo, 166 pp. (in Japanese)

Miyawaki, A. (edt.), (1977). Vegetation of Japan, compared with other regions of the world, Encyclopedia of sci. and techn., Gakken, 3, Tokyo, 535 pp. (in Japanese)

Nogami, M., (1994). Thermal Condition of the Forest Vegetation Zones and their potential Distribution under Different Climates in Japan. Japanese Journal of Geography, 103(7), 886-897. (in Japanese with English abstract)

Ohsawa, M., (1990). An interpretation of latitude patterns of forest limits in South and East Asian mountains. Journal of Ecology, 78, 326-339.

Ohsawa, M., (1995). Latitudinal comparison of altitudinal changes in forest structure, leaf type, and species richness in humid monsoon Asia. Vegetatio, 121, 3-10. 
Harada I., Hara K., Tomita M., Short K., Park J.: Monitoring landscape changes in Japan using classification of MODIS data combined with a Landscape Transformation Sere (LTS) model

Roujean, J. L., Leroy, M., Podaire, A., DesChamps, P. Y., (1992). Evidence of surface reflectance bidirectional effects from a NOAA/AVHRR multi-temporal data set. International Journal of Remote Sensing, 13(4), 685-698.

Toyohara, G., (1984). A phytosociological study and a tentative draft on vegetation mapping of the secondary forests in Hiroshima Prefecture with special reference to pine forests. Journal of science of the Hiroshima University. Series B. Div. 2, Botany, 19(1), 131-170.

Westhoff, V., (1983). Man's attitude towards vegetation, In Holzner, W., Werger, M.J.A., Ikushima, I. (eds.), Man's impact on vegetation (p. 7-24). Junk, The Hague. 